\title{
SPG20 mutation in three siblings with familial hereditary spastic paraplegia
}

\author{
Leila Dardour, ${ }^{1}$ Filip Roelens, ${ }^{2}$ Valerie Race, ${ }^{1}$ Erika Souche, ${ }^{1}$ Maureen Holvoet, ${ }^{1}$ \\ and Koen Devriendt ${ }^{1}$ \\ ${ }^{1}$ Center for Human Genetics, KU Leuven, 3000 Leuven, Belgium; ${ }^{2}$ AZ Delta, 8800 Roeselare, Belgium
}

\begin{abstract}
Troyer syndrome (MIM\#275900) is an autosomal recessive form of complicated hereditary spastic paraplegia. It is characterized by progressive lower extremity spasticity and weakness, dysarthria, distal amyotrophy, developmental delay, short stature, and subtle skeletal abnormalities. It is caused by deleterious mutations in the SPG20 gene, encoding spartin, on Chromosome 13q13. Until now, six unrelated families with a genetically confirmed diagnosis have been reported. Here we report the clinical findings in three brothers of a consanguineous Moroccan family, aged 24, 17, and $7 \mathrm{yr}$ old, with spastic paraplegia, short stature, motor and cognitive delay, and severe intellectual disability. Targeted exon capture and sequencing showed a homozygous nonsense mutation in the SPG20 gene, c.1369C>T (p.Arg457*), in the three affected boys.
\end{abstract}

[Supplemental material is available for this article.]

\section{INTRODUCTION}

Hereditary spastic paraplegias (HSPs) are a group of clinically and etiologically heterogeneous neurodegenerative disorders characterized by progressive spasticity and weakness of lower extremities (Fink 2000). When associated with additional manifestations (e.g., intellectual disability or other organ anomalies), it is called complicated spastic paraplegia. Troyer syndrome (MIM\#275900) is an autosomal recessive complicated HSP associated with dysarthria, pseudobulbar palsy, distal amyotrophy, short stature, and subtle skeletal abnormalities. It is caused by biallelic mutations in the SPG20 gene on Chromosome 13q13, encoding spartin, of which the expression is maximal in the limbs, face, and forebrain primordial during the early stages of embryonic development (Manzini et al. 2010). Three pathogenic SPG20 variants were identified to date: a homozygous single-nucleotide deletion c.1110delA, in an Amish population (Patel et al. 2002), which leads to loss of protein spartin (Bakowska et al. 2008), a homozygous 2-nucleotide deletion c.364_365delTA in Omani, Turkish, and Filipino families, and a homozygous 1-nucelotide substitution c.988A>G (p.Met330Val) in an Israeli-Arab family (Manzini et al. 2010; Tawamie et al. 2015; Butler et al. 2016; Spiegel et al. 2016).

Here we report three brothers of a consanguineous Moroccan family with clinical features of complicated spastic paraplegia. The diagnosis of Troyer syndrome was made after we identified, by targeted exon capture and sequencing, a novel homozygous pathogenic nonsense mutation in the SPG20 gene: (NM_015087.4:c.1369C>T; NC_000013.10: g.36888478G $>A$ ), which resulted in the substitution of arginine by a codon stop in position 457 (p.Arg457*). 


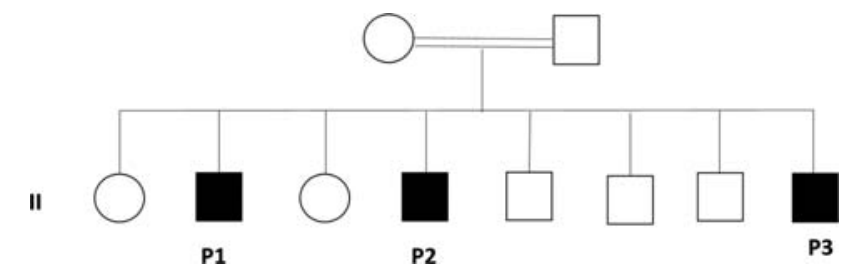

Figure 1. Family pedigree showing the three siblings (P1, P2, and P3).

\section{RESULTS}

\section{Clinical Presentation and Family History}

The three brothers were born to Moroccan first-cousin parents (Fig. 1). There is no known history of intellectual disability or genetic conditions in the family.

\section{Patient 1}

The oldest boy, now aged 24, was born at normal gestational age, with a birth weight of $2865 \mathrm{~g} \mathrm{(-1} \mathrm{SD),} \mathrm{length} 45 \mathrm{~cm}$ (below -2 SD), and head circumference $35 \mathrm{~cm}$ (0 SD). He learned to walk independently at the age of $3 \mathrm{yr}$, and lost this ability at the age of $16 \mathrm{yr}$. Clinical examination at current age shows severe intellectual disability, tetraspasticity with dyskinetic movements, and dysmetry of the upper limbs. He is wheelchair-bound for most of the time, walking only short distances with a walking frame. Speech is absent, but there is some language understanding. He has a short stature with height $145 \mathrm{~cm}$ (below -4 SD), weight $50 \mathrm{~kg}$ (below $-2 \mathrm{SD}$ ), and macrocephaly (head circumference $59.9 \mathrm{~cm},+2$ SD). He has scoliosis. There are no evident dysmorphic features except for heavy eyebrows and malimplanted teeth.

Magnetic resonance imaging (MRI) of the brain was performed at the age of $13 \mathrm{yr}$, showing hyperintense signal in the parieto-occipital regions of the periventricular white matter (Fig. 2A,B).

\section{Patient 2}

The second boy, now aged 17 , is even more severely affected than his older brother.

He was born at normal gestational age, with a birth weight of $3 \mathrm{~kg}(-1 \mathrm{SD})$. He was never able to walk or to speak. Clinical examination at current age shows tetraspasticity (with lower limbs severely affected), dyskinetic movements, severe intellectual disability, staturo-ponderal retardation (weight $18 \mathrm{~kg},-8.6 \mathrm{SD}$, height $117 \mathrm{~cm},-7 \mathrm{SD}$ ), and mild microcephaly (head circumference $52 \mathrm{~cm},-2.1 \mathrm{SD}$ ). He had epicanthic folds, low nasal bridge, protruding ears, malimplanted teeth, and drooling.

Brain MRI at the age of $6.5 \mathrm{yr}$ revealed hyperintense periventricular white matter lesions especially in parieto-occipital and frontal regions (Fig. 2C,D).

\section{Patient 3}

The youngest boy, now aged 7, was born at the gestational age of $38 \mathrm{wk}$ with a weight of $2.970 \mathrm{~kg}(-1 \mathrm{SD})$, length $45 \mathrm{~cm}(-2.5 \mathrm{SD})$, and head circumference $35.7 \mathrm{~cm}(+1 \mathrm{SD})$. There was respiratory distress due to pulmonary hypoplasia, presumably in the context of a small thorax. He was ventilated for $4 \mathrm{~d}$. At the age of $2 \mathrm{wk}$, a subglottis web was diagnosed, treated by dilatation. He had a bicuspid aortic valve. 

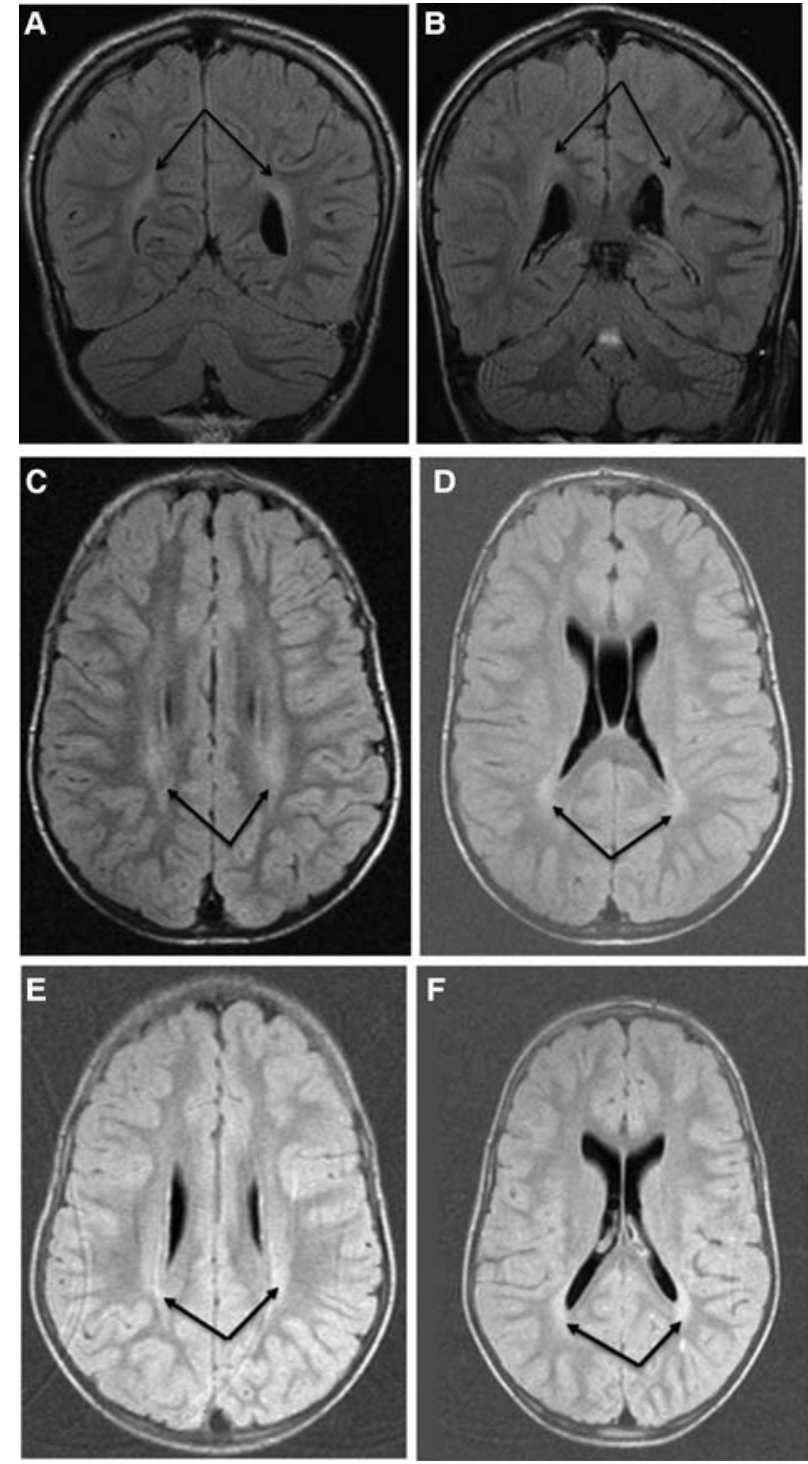

Figure 2. Coronal T2 fluid-attenuated inversion recovery (FLAIR) brain magnetic resonance imaging (MRI) images of Patient $1(A, B)$ and axial T2 FLAIR brain MRI images of Patients $2(C, D)$ and $3(E, F)$ showing hyperintense periventricular white matter lesions, especially in parieto-occipital regions.

At the age of $4 \mathrm{mo}$, when first seen, his weight was $5.460 \mathrm{~g}(-2.2 \mathrm{SD})$, length $55 \mathrm{~cm}(-4.1$ $\mathrm{SD})$, and head circumference $43.7 \mathrm{~cm}$ (+1 SD). The thorax was short, with increased anteroposterior diameter (Fig. 3) . He had a short neck. There was rhizomelic shortening especially of the upper limbs. X-rays of the skeleton did not reveal anomalies. He had a sunken nose bridge and a glabellar nevus flammeus.

Subsequently, there was failure to thrive, with feeding difficulties. There were recurrent respiratory infections. At the age of $5 \mathrm{yr}$, his weight was $11.2 \mathrm{~kg}(-5.3 \mathrm{SD})$, height $87 \mathrm{~cm}$ $(-5.2 \mathrm{SD})$, and head circumference $51.3 \mathrm{~cm}(0.1 \mathrm{SD})$. His development was severely delayed. In the first years of life, he was rather hypotonic. He could sit at the age of 8 mo. He walked independently only at the age of $4.5 \mathrm{yr}$, but his gait was unstable, with frequent falling. Progressively, he developed spasticity, especially of the lower limbs, with clonus and positive 


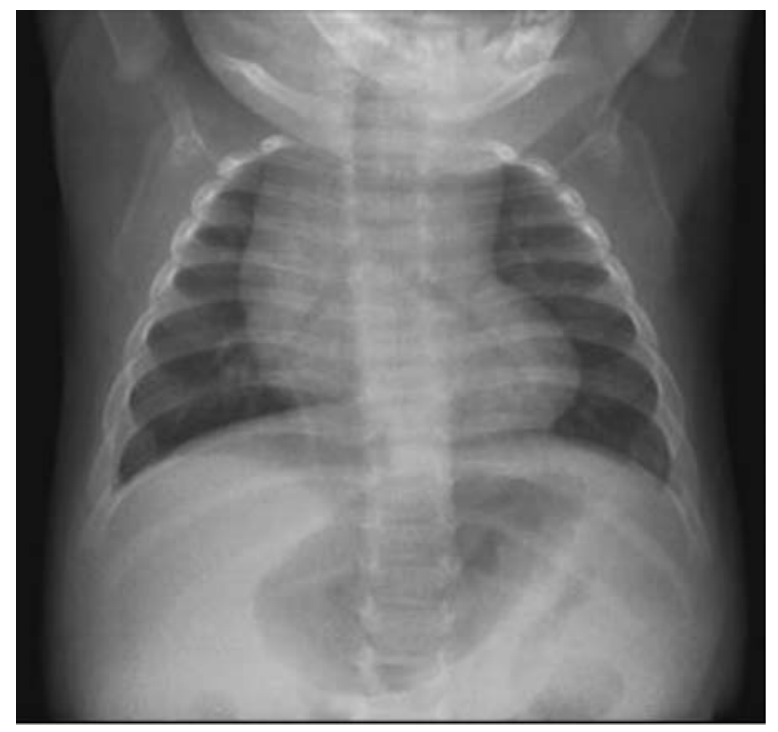

Figure 3. Neonatal chest radiograph of Patient 3 showing the shortening of the thorax.

Babinski response. There were intentional tremor and dysmetric movements of the upper limbs. At the age of $5 \mathrm{yr}$, he could speak only a few words.

MRI of the brain at the age of $6 \mathrm{yr}$ showed hyperintense white matter on fluid-attenuated inversion recovery (FLAIR) and T2, especially in the parieto-occipital regions (Fig. 2E,F).

Extensive neurometabolic tests did not reveal a diagnosis in any of these three siblings. Molecular karyotyping by means of microarray-comparative genomic hybridization (CGH) (version Agilent 60k) was also normal in the three boys.

\section{GENOMIC ANALYSES}

The total number of variants on the TruSight One Panel (using paired-end reads of $151 \mathrm{bp}$, with a mean coverage of $146 \times$ ) was 52,625 , of which 10 were homozygous exonic variants (Table 1).

The only predicted deleterious mutation was a homozygous nonsense mutation found in the SPG20 gene, c.1369C >T (p.Arg457*). The nomenclature of the mutation is based on transcript NM_015087.4. The mutation was classified as pathogenic, because it results in the substitution of an arginine for a stop codon in position 457 that is highly conserved among species (11/12 species Alamut V2.7) and leads to the interruption of the reading frame of the protein. This variant was detected in the Exome Aggregation Consortium (ExAC) Browser. The allele frequency was 0.000008244 , with a probability of loss-of-function intolerance (pLl) value of zero for this gene. No homozygotes were detected.

The sequence variant was deposited in the Database of Chromosomal Imbalance and Phenotype in Humans (DECIPHER) (SPG20 gene, DECIPHER ID 339774).

Subsequently homozygosity for this mutation was confirmed in his two affected brothers by Sanger sequencing (Supplemental Fig. S1), and both parents were found to be a carrier of this mutation. Three other siblings were tested by targeted Sanger sequencing. None was homozygous for the mutation. 


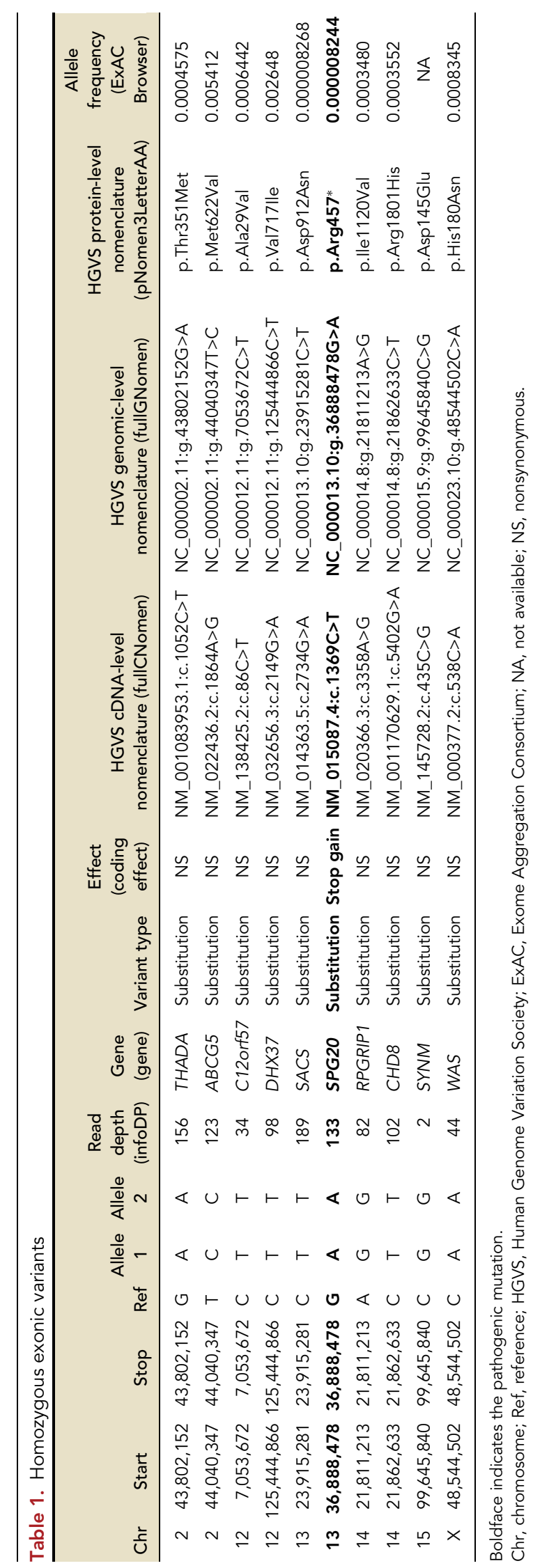




\section{DISCUSSION}

Troyer syndrome, named after the family in which the disorder was first identified, was reported in 1967 as one of the rare autosomal recessive conditions found in the Old Order Amish. Only a few patients with suspected Troyer syndrome were subsequently reported in other populations (Cross and McKusick 1967; Farah et al. 1997; Bertini et al. 1998; Auer-Grumbach et al. 1999).

The genetic cause of Troyer syndrome was identified in 2002 by Patel et al. (2002) in the Amish population. A homozygous 1-nt SPG20 deletion predicted a loss of function of the spartin protein as the disease mechanism (Bakowska et al. 2008).

With the advent of molecular diagnostic testing, additional families are now being identified. The second mutation was first described in Omani families by Manzini et al. (2010), and then found in a Turkish family (Tawamie et al. 2015) and three Filipino patients (Butler et al. 2016). They carried the same mutation c.364_365delTA in exon 2 resulting in a stop codon in the first coding exon (p.Met122ValfsTer2).

A missense mutation was identified in an Israeli-Arab family (c.988A>G (p.Met330Val)) resulting in almost complete loss of spartin in skeletal muscle (Spiegel et al. 2016).

The three siblings presented here carry a new mutation in the SPG20 gene. It is a homozygous transition in exon 6 leading to a nonsense mutation c. $1369 \mathrm{C}>\mathrm{T}$ that predicts the substitution of an arginine codon with a stop codon in position 457 (p.Arg457*).

Our patients share many features with the other described cases including short stature, spastic paraparesis, distal amyotrophy, motor, speech and cognitive delays, and gait abnormalities (Table 2). Microcephaly was noticed in Patient 2, in the Turkish family, and the Filipino patients. On the contrary, Patient 1 had macrocephaly. Affected Old Amish and Turkish patients presented emotional lability.

Skeletal abnormalities were present in all previous cases except the Filipino kindred. In our series, Patient 1 had scoliosis, and Patient 3 had skeletal anomalies involving the thorax.

Brain MRI in three patients of the Amish cohort showed abnormal T2 hyperintense signal in the periventricular white matter and the posterior limb of the internal capsule (Proukakis

\begin{tabular}{|c|c|c|c|c|c|c|}
\hline Clinical features & $\begin{array}{l}\text { Old Amish } \\
\text { (21 patients) }\end{array}$ & $\begin{array}{c}\text { Omani } \\
\text { (six patients) }\end{array}$ & $\begin{array}{c}\text { Turkish } \\
\text { (two patients) }\end{array}$ & $\begin{array}{l}\text { Filipino } \\
\text { (three patients) }\end{array}$ & $\begin{array}{l}\text { Israeli-Arab } \\
\text { (one patient) }\end{array}$ & $\begin{array}{c}\text { Moroccan } \\
\text { (three patients) }\end{array}$ \\
\hline Microcephaly & - & - & + & + & NA & $+/-$ \\
\hline Short stature & + & + & + & + & + & + \\
\hline Intellectual disability, mild & + & + & + & $+/-$ & + & + \\
\hline Motor delay & + & + & + & + & + & + \\
\hline Dysarthria & + & + & + & + & + & + \\
\hline $\begin{array}{l}\text { Delayed speech and } \\
\text { language development }\end{array}$ & + & + & + & + & + & + \\
\hline Gait ataxia & + & + & + & + & + & + \\
\hline Spastic paraparesis & + & + & + & $+/-$ & + & + \\
\hline Distal amyotrophy & + & + & + & + & + & + \\
\hline $\begin{array}{l}\text { Abnormality of the skeletal } \\
\text { system }\end{array}$ & + & + & + & - & + & $+/-$ \\
\hline Brain MRI abnormalities & + & + & - & $+/-$ & - & + \\
\hline SPG20 mutation & c.1110delA & c.364_365delAT & c.364_365delAT & c.364_365delAT & c. $988 \mathrm{~A}>\mathrm{G}$ & c. $1369 C>T$ \\
\hline
\end{tabular}

+, Present; -, absent; NA, not available; MRI, magnetic resonance imaging. 
et al. 2004). The two Omani patients had, on brain MRI, mild atrophy of the cerebellar vermis, mild white matter volume loss, and periventricular white matter hyperintensity on T2-weighted images (Manzini et al. 2010). The Turkish and Israeli-Arab patients had no brain MRI abnormalities (Tawamie et al. 2015; Spiegel et al. 2016). Only one Filipino patient had increased T2/FLAIR signal within the ventrolateral thalami and posterior limb of the internal capsule (Butler et al. 2016). In our cohort, all three patients had hyperintense periventricular white matter lesions on T2/FLAIR, especially in parieto-occipital and frontal regions. These white matter hyperintensities are not seen in the normal population but are nonspecific. For example, they can be present in several other forms of hereditary spastic paraplegia.

Despite these similarities, some specific differences were observed in the present family, including the severe intellectual disability.

In the patients presented in this study, targeted exon capture and sequencing revealed the diagnosis of Troyer syndrome years after their first consultation and several neurometabolic and other genetic investigations. This further highlights the value of diagnostic evaluation via targeted exon capture and sequencing of unresolved cases of HSP.

\section{METHODS}

\section{Identification of the SPG20 Mutation}

Targeted exon capture and sequencing using TruSight One Sequencing Panel Kits (Illumina) was performed on the youngest child. It targets 4813 genes associated with known Mendelian phenotypes. Annotation of the variants was done using the Reference Sequencing Database (RefSeq) (release 64) and Cartagena (version 3). The pipeline analysis was used to extract homozygous variants from the sequence data of the TruSight One Panel (Tables 3 and 4).

Targeted Sanger sequencing was performed in the other family members, using, in addition to the M13 universal primers, these exon 6-specific primers:

SPG20 ex6 For TGT AAA ACG ACG GCC AGT CAT GGC ACA TTT AGC ATC TGA SPG20 ex6 Rev CAG GAA ACA GCT ATG ACC AGG ACG ATG TGA TGT TGC TG

\begin{tabular}{ll}
\hline Table 3. Variant filtering & \\
\hline Clinical exome & 52,626 variants \\
Total number of reads & $29,912,898$ \\
Average read depth & 146 \\
Population frequency (<2\%) & 7905 variants \\
Exonic & 500 variants \\
Exonic indel & 54 variants \\
Exonic nonsynonymous, stop & 243 variants \\
Exonic synonymous & 203 variants \\
Splicing ( \pm ) 20 bp & 533 variants \\
Coding \pm 20 bp & 1033 variants \\
Hypothesis $1=$ AR homozygous variants & $51 / 1033$ variants \\
Exonic indel & 3 variants \\
Exonic nonsynonymous, stop & 10 variants \\
Exonic synonymous & 13 variants \\
Splicing & 25 variants \\
\hline
\end{tabular}

$A R$, autosomal recessive. 
Competing Interest Statement

The authors have declared no competing interest.

\section{Referees}

Gholson Lyon

Anonymous

Received October 14, 2016; accepted in revised form February 23, 2017.
Table 4. Proportion of targeted exons covered by $0,2,10,20$, and 30 reads

\begin{tabular}{ll}
\hline Clusters & $14,956,449$ \\
Reads & $29,912,898$ \\
Reads in binary alignment & $29,739,094$ \\
Unique & $26,924,175$ \\
Unique and aligned & $25,915,934$ \\
Unique and aligned (\%) & 86.63799141 \\
Selected bases & 0.72 \\
Mean target coverage & 146.00 \\
Target at 0x & 0.01 \\
Target at $2 \times$ & 0.99 \\
Target at $10 \times$ & 0.98 \\
Target at 20x & 0.97 \\
Target at $30 \times$ & 0.95 \\
CS1 & 0.952 \\
\hline
\end{tabular}

\section{ADDITIONAL INFORMATION:}

\section{Data Deposition and Access}

The SPG20 variant was deposited in DECIPHER (https://decipher.sanger.ac.uk/) under DECIPHER ID 339774. The targeted sequencing could not deposited because of a lack of patient consent.

\section{Ethics Statement}

Molecular genetic investigations for the three patients and their family were performed after parental informed consent in a clinical diagnostic setting. This study was approved by the KU Leuven university Hospitals Ethical committee (B322201010111-S52853). The patients' family consented to publication of the study.

\section{Author Contributions}

L.D. interpreted data and wrote the manuscript; F.R. followed and treated the patients, performed metabolic investigations and MRI imaging, and contributed to the manuscript writing; V.R. performed the targeted exon capture and sequencing; E.S. analyzed and interpreted data and contributed to the manuscript writing; M.H. ensured the follow-up and genetic counselling for the family and contributed to the manuscript writing; and K.D. followed the patients, performed the different genetic testings after clinical examination, collected blood samples, interpreted data and contributed to the manuscript writing.

\section{REFERENCES}

Auer-Grumbach M, Fazekas F, Radner H, Irmler A, Strasser-Fuchs S, Hartung HP. 1999. Troyer syndrome: a combination of central brain abnormality and motor neuron disease? J Neurol 246: 556-561.

Bakowska JC, Wang H, Xin B, Sumner CJ, Blackstone C. 2008. Lack of spartin protein in Troyer syndrome: a loss-of-function disease mechanism? Arch Neurol 65: 520-524.

Bertini E, Sabatelli M, Di Capua M, Cilio MR, Mignogna T, Federico A, Tonali P. 1998. Familial spastic paraplegia, axonal sensory-motor polyneuropathy and bulbar amyotrophy with facial dysmorphia: new cases of Troyer-like syndrome. Eur J Paediatr Neurol 2: 245-254. 
Butler S, Helbig KL, Alcaraz W, Seaver LH, Hsieh DT, Rohena L. 2016. Three cases of Troyer syndrome in two families of Filipino descent. Am J Med Genet A 170: 1780-1785.

Cross HE, Mc Kusick VA. 1967. The Troyer syndrome. A recessive form of spastic paraplegia with distal muscle wasting. Arch Neurol 16: 473-485.

Farah S, Sabry MA, al-Shubaili AF, Anim JT, Hussain JM, Montaser MA, Sharfuddin KM. 1997. Hereditary spastic paraparesis with distal muscle wasting, microcephaly, mental retardation, arachnodactyly and tremors: new entity? Clin Neurol Neurosurg 99: 66-70.

Fink JK. 2000. Last Update: 2014. Hereditary spastic paraplegia overview. GeneReviews. https://www.ncbi.nlm. nih.gov/books/NBK1509/.

Manzini MC, Rajab A, Maynard TM, Mochida GH, Tan WH, Nasir R, Hill RS, Gleason D, Al Saffar M, Partlow JN, et al. 2010. Developmental and degenerative features in a complicated spastic paraplegia. Ann Neurol 67: 516-525.

Patel H, Cross H, Proukakis C, Hershberger R, Bork P, Ciccarelli FD, Patton MA, McKusick VA, Crosby AH. 2002. SPG2O is mutated in Troyer syndrome, an hereditary spastic paraplegia. Nat Genet 31: 347-348.

Proukakis C, Cross H, Patel H, Patton MA, Valentine A, Crosby AH. 2004. Troyer syndrome revisited. A clinical and radiological study of a complicated hereditary spastic paraplegia. J Neurol 251: 1105-1110.

Spiegel R, Soiferman D, Shaag A, Shalev S, Elpeleg O, Saada A. 2016. Novel homozygous missense mutation in SPG20 gene results in Troyer syndrome associated with mitochondrial cytochrome coxidase deficiency. JIMD Rep. doi: 10. 1007/8904_2016_580

Tawamie H, Wohlleber E, Uebe S, Schmal C, Nothen MM, Abou Jamra R. 2015. Recurrent null mutation in SPG20 leads to Troyer syndrome. Mol Cell Probes 29: 315-318. 


\section{COLD SPRING HARBOR Molecular Case Studies}

\section{SPG20 mutation in three siblings with familial hereditary spastic paraplegia}

Leila Dardour, Filip Roelens, Valerie Race, et al.

Cold Spring Harb Mol Case Stud 2017, 3: a001537 originally published online April 4, 2017

Access the most recent version at doi: $10.1101 /$ mcs.a001537
Supplementary http://molecularcasestudies.cshlp.org/content/suppl/2017/04/04/mcs.a001537.D Material C1
License This article is distributed under the terms of the Creative Commons Attribution-NonCommercial License, which permits reuse and redistribution, except for commercial purposes, provided that the original author and source are credited.
Email Alerting Receive free email alerts when new articles cite this article - sign up in the box at the Service top right corner of the article or click here.

